\title{
The p53 codon 72 proline allele is endowed with enhanced cell-death inducing potential in cancer cells exposed to hypoxia
}

\author{
P Sansone ${ }^{1,2,4}$, G Storci ${ }^{1,3,4}$, S Pandolfi', L Montanaro ${ }^{3}$, P Chieco' and M Bonafée, 1,3 \\ 'Center for Applied Biomedical Research (CRBA), St. Orsola-Malpighi University Hospital, Bologna, Italy; ${ }^{2}$ Department of Pharmacology and Toxicology, \\ University of Bologna, Bologna, Italy; ${ }^{3}$ Department of Experimental Pathology, University of Bologna, Bologna, Italy
}

The preferential retention of the arginine allele at the p53 codon 72 locus is commonly observed in tumours from arginine/proline heterozygotes. Considering that cancer cells are harboured in a hypoxic environment in vivo, we here tested the hypothesis that the p53 codon 72 proline allele confers a survival disadvantage in presence of hypoxia. Here, we show that the transient transfection of the proline allele in $\mathrm{p} 53$ null cancer cells exposed to low oxygen tension or to the hypoxia-mimetic drug Desferoxamine induces a higher amount of cell death than the arginine allele. Accordingly, proline allele transiently transfected cell lines express lower levels of hypoxia pro-survival genes (HIF-I $\alpha$, carbonic anhydrase IX, vascular endothelial growth factor, heme oxygenase-l, hepatocyte growth factor receptor, vascular endothelial growth factor receptor 2), compared to those transiently transfected with the arginine allele. Further, we report that the exposure of the arginine/proline heterozygote MCF-7 breast cancer cell line to cytotoxic concentration of Desferoxamine for several weeks, gives raise to hypoxia-resistant clones, carrying the arginine, but not the proline allele. These data indicate that the p53 codon 72 proline allele is less permissive for the growth of cancer cells in a hypoxic environment, and suggest that the preferential retention of the arginine allele in the tumour tissues of arginine/proline heterozygous patients may depend upon its lowered capacity to induce cell death in a hypoxic tumour environment. British Journal of Cancer (2007) 96, I302- |308. doi:I0.1038/sj.bjc.6603723 www.bjcancer.com Published online 3 April 2007 (C) 2007 Cancer Research UK

Keywords: p53; codon 72; polymorphism; hypoxia

The codon 72 arginine-to-proline polymorphism at the p53 locus affects cancer development, as well as response to therapy and survival of cancer patients (Thomas et al, 1999; Marin et al, 2000; Bergamaschi et al, 2003; Bonafe et al, 2003). The N-terminal polyproline-rich domain, in which the polymorphism is harboured, interacts with numerous proteins that are active players in the process of gene transcription and cell death (Baptiste et al, 2002). In particular, the two p53 codon 72 alleles show a functional difference in the binding to transcription factors (e.g., TAF30II) and in the interaction with the cell death regulatory proteins MDM-2, Bcl-2, Bcl-xL and iASPP (Matlashewski et al, 1987; Dumont et al, 2003; Bonafe et al, 2004; Hammond and Giaccia, 2005; Bergamaschi et al, 2006). The arginine allele is preferentially retained (i.e., the proline allele is preferentially lost) in cancer cells and in tumour tissues of arginine/proline heterozygous cancer affected patients (Brooks et al, 2000; Anzola et al, 2003; Bonafe et al, 2003; Schneider-Stock et al, 2004). The phenomenon has been attributed to the inactivation of the pro-apoptotic TP73 gene induced by the mutated arginine, but not proline allele (Marin et al, 2000). In fact, several reports indicate that the arginine allele is a better inducer of apoptosis in vitro (Bonafe et al, 2002, 2004; Dumont et al, 2003). However, the relevance of such a functional

\footnotetext{
*Correspondence: Dr M Bonafé;

E-mail: massimiliano.bonafe@unibo.it

${ }^{4}$ These two authors equally contributed to this work.

Received 26 October 2006; revised 5 March 2007; accepted 8 March 2007; published online 3 April 2007
}

difference between the p53 codon 72 alleles for tumour growth in vivo has not yet been understood. Wild-type p53 protein induces cell death in response to hypoxia (Graeber et al, 1996; Semenza, 2003). Clones of cells lacking active p53 have a survival advantage in a hypoxic environment (Graeber et al, 1996), consistently, the hypoxic environment present in the tumour mass in vivo is supposed to select clones carrying defective p53 (Graeber et al, 1996; Semenza, 2003). Interestingly, the p53-mediated suppression of hypoxia survival genes, such as carbonic anhydrase IX and vascular endothelial growth factor has been reported (Koumenis et al, 2001; Pal et al, 2001; Kaluzova et al, 2004). Such a repressor activity has been proposed to be more relevant than the p53mediated induction of pro-apoptotic genes in determining cell death in presence of hypoxia (Hammond and Giaccia, 2005; Hammond et al, 2006). We here tested the hypothesis that the p53 codon 72 alleles differ in the capacity to induce cell death in presence of hypoxia. We found that the proline allele confers a survival disadvantage to cancer cells exposed to hypoxic environment. We speculate that such a difference will help to understand the mechanism at the basis of the preferential retention of the arginine allele in tumour tissues in vivo.

\section{MATERIALS AND METHODS}

\section{Cell culture and reagents}

All culture media (Rosewell Park Memorial Institute (RPMI)-1640, F-12K, Low glucose Dulbecco's modified Eagle's medium 
A

MCF-7

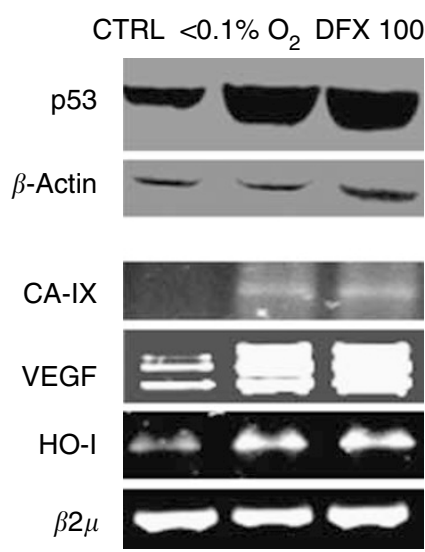

B
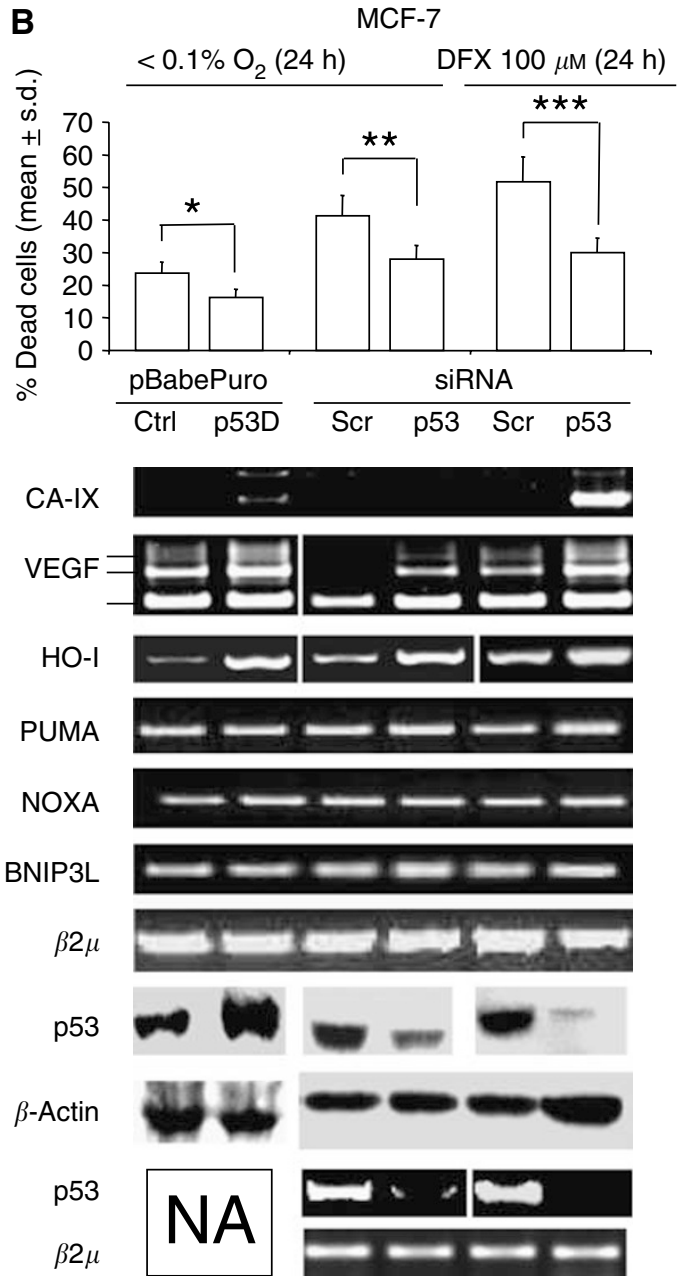

Figure I The inactivation and the downregulation of p53 enhances survival of MCF-7 cells in presence of hypoxia. (A) Exposure to severe hypoxia $\left(<0.1 \% \mathrm{O}_{2}\right)$ or to $100 \mu \mathrm{M}$ DFX for $24 \mathrm{~h}$ : Western blot (WB) analysis of p53 protein, RT-PCR analysis of carbonic anhydrase IX (CA-IX), VEGF, heme oxygenase-I (HO-I) (B) MCF-7 cells infected with a pBabePuro retroviral vector, empty (Ctrl) or encoding a p53 dominant-negative mini-protein (p53D), or exposed to a p53-specific or control ( $\mathrm{Scr}$ ) siRNA: cell death analysis, $n=3$, * $P=0.008$; $* * P=0.043$; $* * * P=0.015$; ANOVA test, data are expressed as mean \pm s.d. (upper panel); RT-PCR analysis of CA-IX, VEGF, HO-I, PUMA, NOXA, BNIP3L and $\beta 2 \mu \mathrm{m}$ RNA level (middle panel), WB and RT-PCR analysis of 553 protein and mRNA level (lower panel).

(DMEM)), fetal bovine serum (FBS), L-glutamine, penicillin/ streptomycin were purchased from Euroclone (Milan, Italy). MCF-7 cells were grown in RPMI-1640 medium, supplemented with 10\% FBS; PC-3 cells were grown in F-12K medium supplemented with $10 \%$ FBS; HEP-3B cells were grown in low glucose DMEM, supplemented with 10\% FBS; MDA-MB-157 cells were grown in 50:50 mixture of DMEM/F-12K media, supplemented with $5 \%$ FBS. All the cultures were kept at $37^{\circ} \mathrm{C}$ in a $5 \%$ $\mathrm{CO}_{2}$-humidified atmosphere.

\section{Exposure to severe hypoxia and to the hypoxia mimetic desferoxamine}

Severe hypoxia $\left(<0.1 \% \mathrm{O}_{2}\right)$ was generated in a humidified incubator supplied with $95 \% \mathrm{~N}_{2} / 5 \% \mathrm{CO}_{2}$ (Thermoforma, Thermo, Waltham, MA, USA). Desferoxamine (DFX) (Sigma, St. Louis, MO, USA) was used as hypoxia mimetic. MCF-7 cells were exposed to various concentrations of DFX $(100-500 \mu \mathrm{M})$, for 4 weeks. After a massive cell death, several (20) clones were isolated in $100 \mu \mathrm{M}$ administered cultures, and were genotyped for the p53 codon 72 polymorphism (Supplementary Figure 1). No clones were obtained when $>100 \mu \mathrm{M}$ of DFX was used. The clone endowed with the best capacity of in vitro growth (clone number 7, HYPO-7) was extensively passaged and cultured for at least 1 year in absence of DFX, without appreciable changes in morphology and gene expression (Supplementary Figure 2).

\section{Transient transfection of the p53 codon 72 alleles encoding plasmids}

Plasmids encoding the $\mathrm{p} 53$ codon 72 proline or arginine allele were obtained by cloning the entire p53cDNA into a pCMS-GFP expression vector (Clontech, Palo Alto, CA, USA), as described elsewhere (Bonafe et al, 2004). To perform transient transfection in $3 \mathrm{~cm}^{2}$ wells, $60 \%$ confluent cells were incubated with $800 \mathrm{ng}$ of plasmid for $24 \mathrm{~h}$, in the presence of the transfection reagent Lipofectamine 2000 at a ratio of $1: 3$ (Invitrogen, Carlsbad, CA, USA). Transfection efficiency was scored using fluorescent microscopy of the GFP-expressing cells.

\section{Stable retroviral tranduction with dominant-negative mini p53 protein}

Retroviral gene transfer was performed as described previously (Per et al, 1993). Briefly, Phoenix cells (kindly provided by Dr K Marcu, Department of Molecular Biology, University of New York 
A

$\frac{\text { PC-3 }}{100 \mu \mathrm{M} \text { DFX }(24 h) \quad \frac{H E P-3 B}{\text { h }}<0.1 \% \mathrm{O}_{2}(24 \mathrm{~h})}$

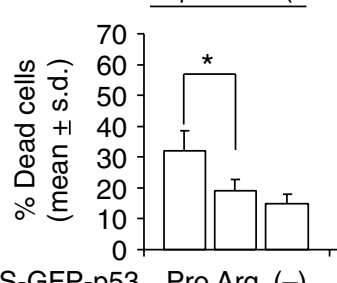

pCMS-GFP-p53 Pro Arg (-)

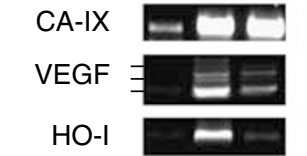

c-MET

KDR

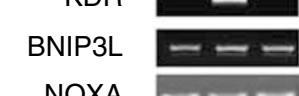

NOXA

PUMA
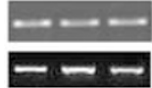

$\beta 2 \mu$

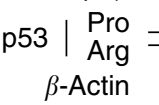
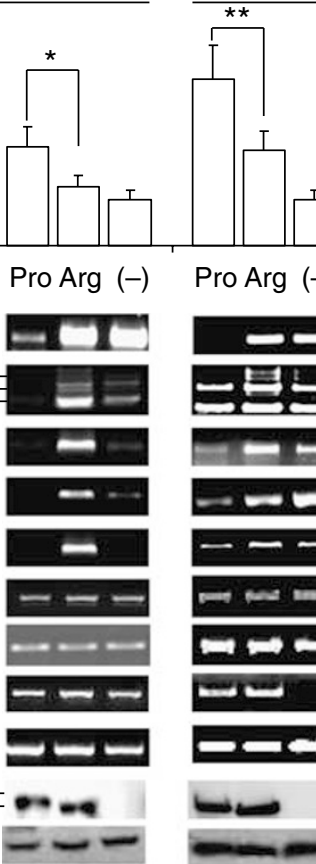

Pro Arg (-)
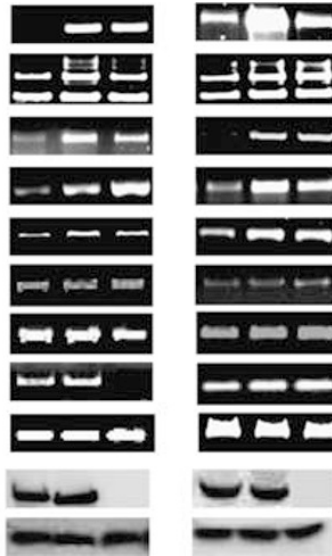

C

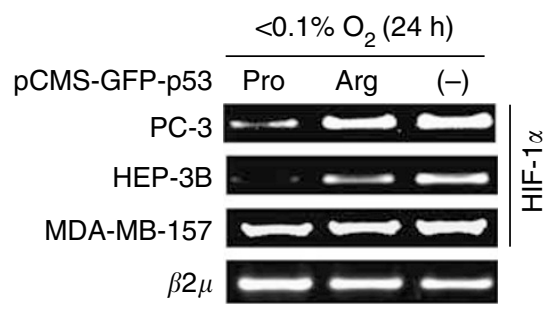

B
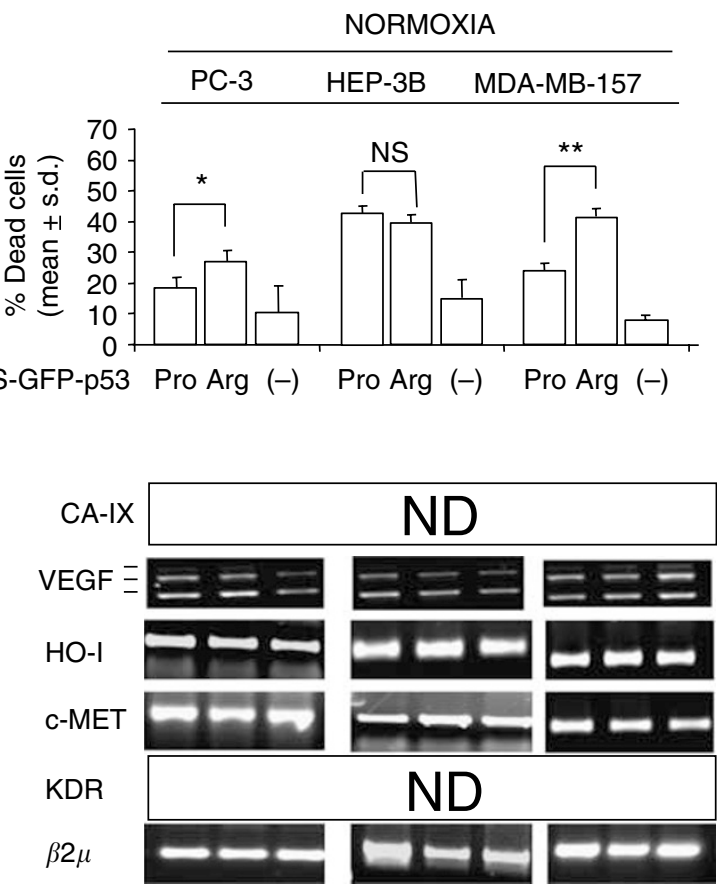

HEP-3B

D

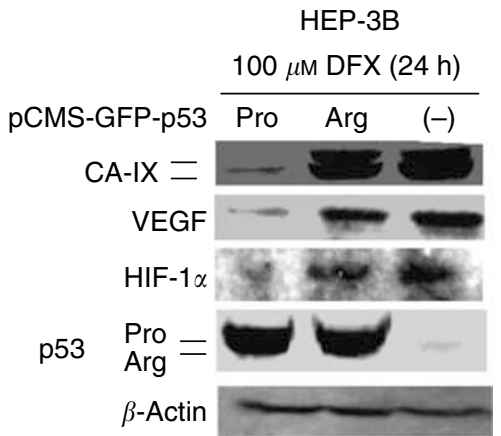

Figure 2 The 553 codon 72 proline allele is more cytotoxic with respect to arginine allele in presence of hypoxia. PC-3 cells exposed to I00 $\mu \mathrm{M}$ DFX, HEP-3B and MDA-MB- 157 exposed to $<0.1 \% \mathrm{O}_{2}$, transiently transfected with p53 codon 72 arginine- (p53Arg) or proline- (p53Pro) allele encoding, or empty $(-)$ pCMS-GFP expression vector. $(\mathbf{A})$ cell death analysis $(n=3)$, * $P=0.016$; *** $P=0.006 ; * * * P=0.008$; Bonferroni-corrected post hoc test, data are expressed as mean \pm s.d. (upper panel); RT-PCR analysis of CA-IX, VEGF, HO-I, c-MET, KDR, BNIP3L, NOXA, PUMA and $\beta 2 \mu$ m RNA level (middle panel); Western blot analysis of $\mathrm{p} 53$ and $\beta$-actin (Note the faster migration rate of the p53Arg, with respect to the p53Pro allele, lower panel), (B) cell death analysis $(n=3)$, $* P=0.049$; ** $P=0,016$; NS = not significant; Bonferroni-corrected post hoc test; data are expressed as mean \pm s.d. (upper panel), RT-PCR analysis of VEGF, HO- I, c-MET, $\beta 2 \mu$ mRNA level; ND, not detectable (lower panel), (C) RT-PCR analysis of HIF- $\mid \alpha$ and $\beta 2 \mu \mathrm{m}$ RNA level in PC-3, MDA157, HEP-3B cells, exposed to $<0.1 \% \mathrm{O}_{2}$ for $24 \mathrm{~h}$ and transfected with p53Arg or p53Pro or (-) pCMS-GFP vector. (D) Western blot analysis of CA-IX, VEGF, HIF- $\mid \alpha$, p53, $\beta$-actin in HEP-3B cells, exposed to $100 \mu \mathrm{M}$ DFX for $24 \mathrm{~h}$ and transiently transfected with p53Arg or p53Pro or (-) pCMS-GFP vector. Transfection efficiency was evaluated by fluorescent microscopy analysis of GFP-positive cells (data not shown).

at Stony Brook, New York, USA) were grown at $85 \%$ confluence and were transfected overnight with $10 \mu \mathrm{g}$ of the retroviral pBabepuro plasmid, either empty or encoding a dominant negative p53-miniprotein (p53D), provided by Dr M. Oren (The Weizman Institute Rehovot, Israel). P53D is a C-terminal fragment of p53 that retains the multimerisation, but not the transcriptional transactivation domain, and it forms transcriptionally inactive multimers with endogenous wild-type p53 protein, which in turn accumulate in the cells owing to the lack of MDM2-mediated degradation (Shaulian et al, 1992). Two days after transfection, the medium containing newly packaged retrovirus was collected and filtered through a $0.45-\mu \mathrm{m}$ pore size filter. After supplementation with $4 \mu \mathrm{g} \mathrm{ml}^{-1}$ polybrene (Sigma), the augmented medium was applied to MCF-7 cells at $50 \%$ for $24 \mathrm{~h}$. Puromycin $2 \mu \mathrm{g} \mathrm{ml}^{-1}$ (Sigma) was used as a selection agent to isolate successfully transduced cells.

\section{Double-strand RNA oligonucleotide-mediated p53 gene silencing}

For the oligonucleotide-mediated silencing of the p53 gene we used predesigned p53-specific short interfering doublestrand RNA oligonucleotide (GCAUGAACCGGAGGCCCA sense, AUGGGCCUCCGGUUCAUG, antisense) and a non-specific short interfering RNA (siRNA) control oligonucleotide (UUCU CCGAACGUGUCACG sense, ACGUGACACGUUCGGAGA, antisense), (Qiagen, Valencia, CA, USA). Transfection procedures were performed using Lipofectamine 2000 (Invitrogen). Briefly, $60 \%$ confluent MCF-7 cells were incubated with $1 \mu \mathrm{g}$ of p53 or control siRNA for $4 \mathrm{~h}$, and then incubated for additional $24 \mathrm{~h}$ in fresh complete RPMI-1640 medium supplemented with $10 \%$ FBS. The efficiency of gene silencing ranged between 70 and $90 \%$. 
p53 codon 72 genotype, p53 cDNA sequencing, loss of heterozygosity at $\mathrm{p} 53$ locus analyses

The DNA and cDNA sequences containing the p53 codon 72 polymorphism were amplified using a standard PCR protocol with the following primers: $F W, 5^{\prime}$-GAC CCAGGTCCAGATGAAGCT- $3^{\prime}$, $R V, 5^{\prime}$-ACCGTAGCTGCCCTGGTAGGT-3'. PCR conditions were as follows: initial denaturation at $94^{\circ} \mathrm{C}$ for $3 \mathrm{~min}, 29$ cycles with denaturation at $94^{\circ} \mathrm{C}$ for $1 \mathrm{~min}$, annealing at $63.5^{\circ} \mathrm{C}$ for $1 \mathrm{~min}$ and extension at $72^{\circ} \mathrm{C}$ for $1 \mathrm{~min}$, followed by final extension at $72^{\circ} \mathrm{C}$ for $7 \mathrm{~min}$. The $156 \mathrm{bp}$ PCR product was digested with restriction enzyme BstUI (New England Biolabs, Beverly, MA, USA), which recognises a restriction site on the arginine allele, yielding a $109 \mathrm{bp}$ fragment (and an undetectable band of $47 \mathrm{bp}$ ). The entire p53 cDNA was amplified by using the following primers, 5 -GCCATG GAGGAGCCGCAGTC- ${ }^{\prime}$ and 5'-TCAGTCTGAGTCAGGCCCTT- ${ }^{\prime}$. The $1189 \mathrm{bp}$ fragment was sequenced in a CEQ8000 Automatic Sequencer (Beckman, Fullerton, CA, USA), using the following primers: $5^{\prime}$-GCCATGGAGGAGCCGCAGTC- $3^{\prime} ; 5^{\prime}$-GCCCCTCCTCA GCATCTTAT- $3^{\prime} ; 5^{\prime}$-TCAGTCTGAGTCAGGCCCTT-3'; $5^{\prime}$-GACCCA GGTCCAGATGAAGCT-3'; $5^{\prime}$-ACCGTAGCTGCCCTGGTAGGT- ${ }^{\prime}$. The sequence analysis revealed the presence of a wild type TP53 in both MCF-7 and HYPO-7 (data not shown). Loss of heterozygosity at p53 locus was assessed by amplifying the 100-120 bp region located in Intron I of the TP53 gene, using the following primers: $5^{\prime}$-ACTCCAGCCTGGGCAATAAGAGCT- $3^{\prime} ; 5^{\prime}$-ACAAACA TCCCCTACCAAACAGC- $3^{\prime}$. Previous reports indicate that the above region is in tight linkage with p53 codon 72 locus (Schneider-Stock et al, 2004). The amplified fragments were separated on an ethidium bromide-stained $2 \%$ agarose gel.

\section{RNA extraction and reverse transcription cDNA amplification}

Total RNA was extracted from cells using TRIzol ${ }^{\circledR}$ Reagent (Invitrogen) according to the manufacturer's instructions. Reverse transcription reaction was performed in a $20 \mu \mathrm{l}$ volume with $2 \mu \mathrm{g}$ of total RNA using the M-MLV Reverse Transcriptase (Invitrogen), following the manufacturer's protocol. Oligo- $(\mathrm{dT})_{12-18}$ primers (Invitrogen) were used for the first strand synthesis. The following primers were used to amplify the target genes mRNA: vascular endothelial growth factor (VEGF): FW: $5^{\prime}$-GAGAATTCGGCCTCCG AAACCATGAACTTTCTGCT- $3^{\prime}$ and RV: 5'-GAGCATGCCCTCC TGCCCGGCTCACCGC- $3^{\prime}$, annealing temperature $65^{\circ} \mathrm{C}$, amplicons length: 520, 600 and $675 \mathrm{bp}$; carbonic anhydrase IX (CA-IX): FW: 5'-CAGGGACAAAGAAGGGGATGAC-3'; RV: 5'-TTGGAAGT AGCGGCTGAAGTCA-3', annealing temperature $61^{\circ} \mathrm{C}$, amplicon length $589 \mathrm{bp}$; Heme Oxigenase-I (HO-I): FW: 5'-CCCGACAGC ATGCCCCAGGAT-3'; RV: 5'-GGAGTTCATGCGGGAGCGGTA GAG-3', annealing temperature $60^{\circ} \mathrm{C}$, amplicon length $549 \mathrm{bp}$; hepatocyte growth factor receptor (c-MET): FW: $5^{\prime}$-ACAGTGGC ATGTCAACATCGCT-3'; RV: 5'-CTTAGACATCTGATGGCTCG-3', annealing temperature $62^{\circ} \mathrm{C}$, amplicon length $656 \mathrm{bp}$; vascular endothelial growth factor receptor-2 (KDR): FW: $5^{\prime}$-TATAGAT GGTGTAACCCGGA-3'; RV: 5' -TTTGTCACTGAGACAGCTTGG-3', annealing temperature $62 \mathrm{C}$, amplicon length $656 \mathrm{bp}$; Hypoxia Induced Factor-1alpha (HIF-1 $\alpha)$ : FW: $5^{\prime}$-GGTGAATATGTCT GGGTTGAAAC-3'，RV: 5'-TGGGACTATTAGGCTCAGGTGAA-3', annealing temperature $56^{\circ} \mathrm{C}$, amplicon length $615 \mathrm{bp}$; PUMA: 5'-CAGACTGTGAATCCTGTGCT- $3^{\prime}$ RV: $5^{\prime}$-ACAGTATCTTACA GGCTGCC- $3^{\prime}$, annealing temperature: $62^{\circ} \mathrm{C}$, amplicon length: 285 bp; NOXA: FW: $5^{\prime}$-GTGCCCTTGGAAACGGAAGA-3', RV: $5^{\prime}$-CCAGCCGCCCAGTCTAATCA- $3^{\prime}$, annealing temperature: $64^{\circ} \mathrm{C}$, amplicon length: $258 \mathrm{bp}$; BNIP3L: FW: $5^{\prime}$-CTCAGTCAGAA GAAGAAGTTGTAG A-3', RV: 5'-CTCAGTCGCTTTCCAATATA GAT-3', annealing temperature $51^{\circ} \mathrm{C}$, amplicon length: $283 \mathrm{bp}$; $\beta 2$-microglobulin $(\beta 2 \mu)$ : FW:5' -ACCCCCACTGAAAAAGATGA-3'; $\mathrm{RV}$ : 5'-ATCTTCAAACCTCCATGATG-3', annealing temperature $58^{\circ} \mathrm{C}$, amplicon length $114 \mathrm{bp}$. All PCR protocols were performed as follows: predenaturation step at $95^{\circ} \mathrm{C}$ for $2 \mathrm{~min} ; 28$ cycles of denaturation at $95^{\circ} \mathrm{C}$ for $1 \mathrm{~min}$, annealing at the appropriate temperature for $1 \mathrm{~min}$, extension at $72^{\circ} \mathrm{C}$ for $1 \mathrm{~min}$; final extension at $72{ }^{\circ} \mathrm{C}$ for $7 \mathrm{~min}$. Amplified fragments were resolved onto a $1.8 \%$ agarose gel.

\section{Western blot analysis}

Cell lysates were prepared using coimmunoprecipitation buffer (10 mm HEPES, $142 \mathrm{~mm} \mathrm{KCl}, 2.5 \mathrm{MgCl}_{2}, 1 \mathrm{~mm}$ EDTA, $1 \mathrm{~mm}$ DTT, $0.2 \% \mathrm{NP}-40)$ supplemented with a protease and phosphatase inhibitors cocktail (Sigma). Total protein lysate $(100 \mu \mathrm{g})$ was loaded onto an $8 \%$ acrylamide/bis-acrylamide gel, and transferred to Hybond, nitrocellulose membrane (Amersham Biosciences, Buckingamshire, UK). Antibodies for WB analysis were directed against: p53 (DO-I Mouse Monoclonal antibody, Santa Cruz Biotechnology, Santa Cruz, CA), CA-IX (Mouse Monoclonal antibody, Clone M75, kindly provided by J Pastorek, Slovak Academy of Sciences, Bratislava, Slovak Republic), HIF- $1 \alpha$ and VEGF (Rabbit Polyclonal Antibodies, Upstate, Charlottesville, VA, USA), $\beta$-actin (Sigma). HRP-conjugated secondary antibodies were visualised by the luminol/enhancer chemiluminescent substrate (Amersham Biosciences).

\section{Cell death assessment}

Cell death was evaluated by propidium iodide exclusion and analysed in a FACSaria (Becton Dickinson, San Josè, CA, USA)

\section{Statistical analysis}

Associations among variables were verified using Student's $t$-test or analysis of variance (ANOVA). Bonferroni-corrected post hoc test was used for pairwise comparisons following a significant $F$-test. Statistical calculations were executed with SPSS 10.1 Software Package (SPSS Inc, Chicago, IL, USA). Data in graphs are expressed as mean \pm s.d.

\section{RESULTS}

p53 promotes cell death and represses the expression of hypoxia pro-survival genes in MCF-7 cells exposed to hypoxia

We began this investigation by examining the role of the p53 inactivation in hypoxia-induced cell death in MCF-7. First, we generated a puromycin-resistant MCF-7 polyclonal population stably transduced with a pBabe retroviral vector, either empty or encoding a dominant-negative mini p53 protein (p53D), which hampers the activity of p53 by accumulating the protein in the cytoplasm (Shaulian et al, 1992). Second, we transiently transfected parental MCF-7 cells with a p53-specific short interfering RNA (p53 siRNA), which brings to a substantial reduction in the p53 mRNA level. We then exposed the cells to severe hypoxia $(<0.1 \%$ $\mathrm{O}_{2}$ ) or to the hypoxia mimetic DFX, at a concentration of $100 \mu \mathrm{M}$, and we found that both p53D-transduced cells and p53siRNAtransfected MCF-7 cells exhibited a significantly lower rate of cell death in comparison to the matched controls (Figure 1B, upper panel). The phenomenon was paralleled by a marked increase in the mRNA level of hypoxia response genes (Lee et al, 1997; Pal et al, 2001; Kaluzova et al, 2004) namely, VEGF, carbonic anhydrase IX (CA-IX), heme oxygenase-I (HO-I, Figure 1B, middle panel). Interestingly, no differences were observed as far as hypoxia-response/p53 regulated genes such as BNIP3L, PUMA and NOXA are concerned see Figure $1 \mathrm{~B}$, (middle panel). These data indicate that, in our experimental conditions, the lack of p53 

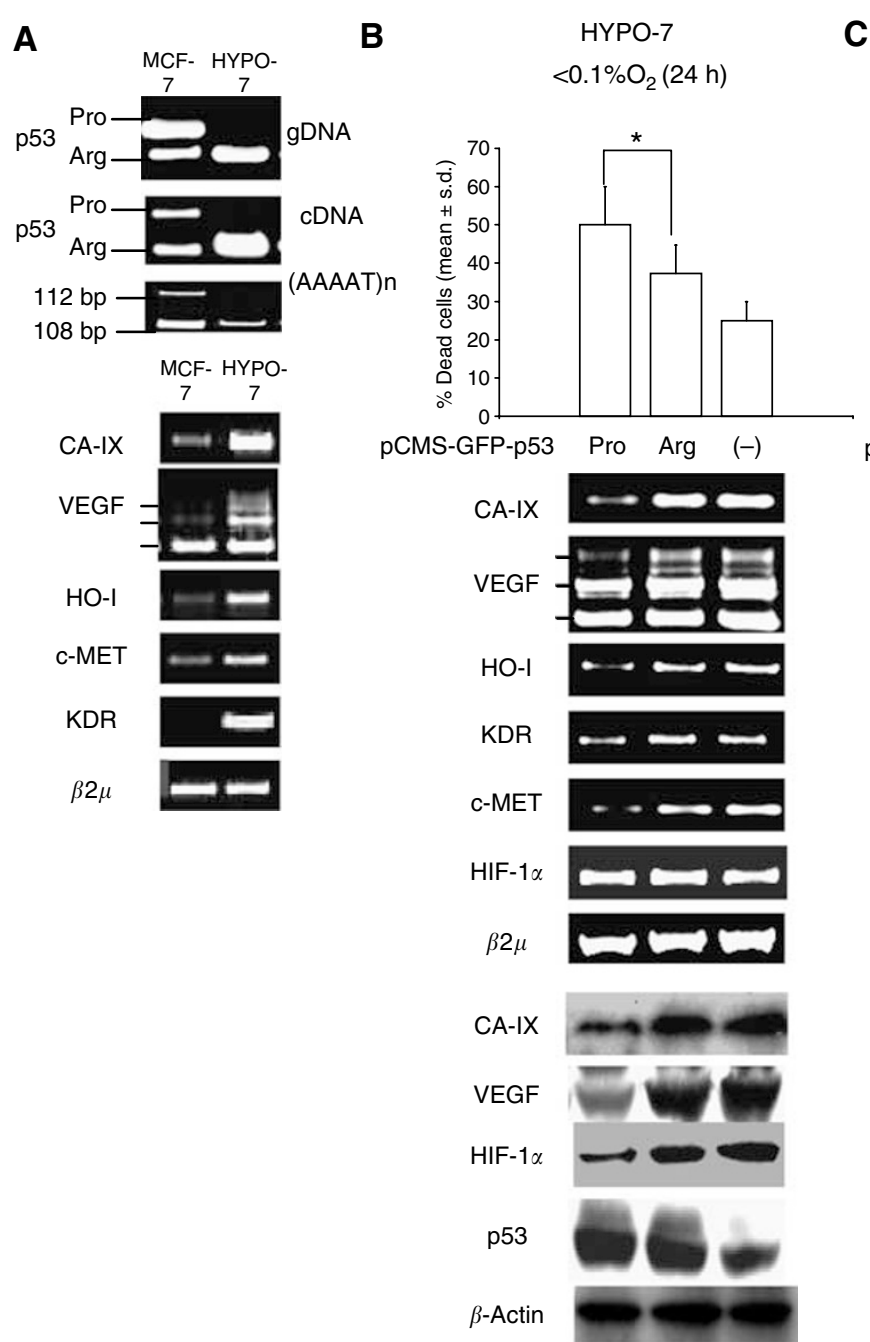

C$$
\begin{gathered}
\mathrm{MCF}-7 / \mathrm{p} 53 \mathrm{D} \\
<0.1 \% \mathrm{O}_{2}(24 \mathrm{~h})
\end{gathered}
$$

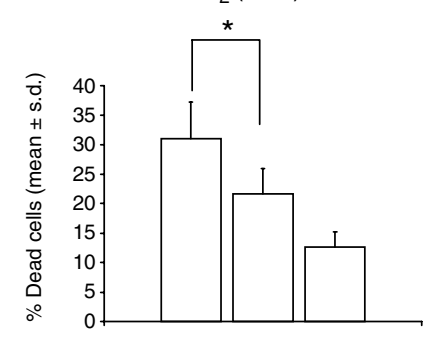

pCMS-GFP-p53 Pro Arg (-)

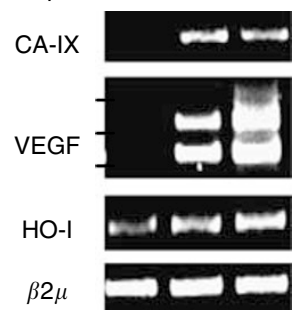

$\beta 2 \mu$

Figure 3 The p53Arg is retained in MCF-7-derived hypoxia-selected clones. (A) HYPO-7 and MCF-7 cells: PCR analysis of p53 codon 72 genotype on
genomic DNA (gDNA) and cDNA, Loss of heterozygosity at the (AAAAT) pentanucleotide repeat located in the Intron I of the TP53 gene (upper); RTPCR analysis of CA-IX, VEGF, HO-I, c-MET, KDR and $\beta 2 \mu \mathrm{m}$ RNA level (lower). (B) HYPO-7 cells exposed to <0.1\% $\mathrm{O}_{2}$ for $24 \mathrm{~h}$ and transiently transfected with p53Arg, p53Pro (-) pCMS-GFP vector: Cell death analysis $(n=3)$, *P=0.028; Bonferroni-corrected post hoc test, data are expressed as mean \pm s.d. (upper); RT-PCR analysis of CA-IX, VEGF, HO-I, KDR, c-MET, HIF-I $\alpha$ and $\beta 2 \mu \mathrm{m}$ RNA level (middle); Western blot analysis of CA-IX, VEGF, $\mathrm{HIF}-\mathrm{|} \alpha, \mathrm{p} 53$ and $\beta$-actin (lower). (C) pBabe-p53D stably transduced MCF-7 (MCF-7/p53D), exposed to $<0.1 \% \mathrm{O}_{2}$ for $24 \mathrm{~h}$, and transiently transfected with p53Arg, p53Pro or (-) pCMS-GFP vector: cell death analysis $(n=3)$, *P=0.035; Bonferroni-corrected post hoc test, data are expressed as mean \pm s.d. (upper); RT-PCR analysis of CA-IX, VEGF, HO-I and $\beta 2 \mu \mathrm{m}$ RNA level (lower). Transfection efficiency was evaluated by fluorescent microscopy analysis of GFP positive cells (data not shown).

activity favours hypoxia survival and prevents the downregulation of hypoxia response genes.

\section{The transfection of the p53 codon 72 proline allele enhances cell death in cancer cells exposed to hypoxia}

To ascertain whether the p53 codon 72 alleles show a functional difference with regards to cell survival and regulation of hypoxia response genes, p53-null cells (the breast cancer cell line MDAMB-157, the hepatocellular carcinoma cell line HEP-3B, the prostate carcinoma cell line $\mathrm{PC}-3$ ) were exposed to $<0.1 \% . \mathrm{O}_{2}$ and/or to $100 \mu \mathrm{M} \mathrm{DFX,} \mathrm{and} \mathrm{then} \mathrm{transiently} \mathrm{transfected} \mathrm{with} \mathrm{a}$ pCMS-GFP vector, either empty (-), or encoding the p53 codon 72 arginine ( $\mathrm{p} 53 \mathrm{Arg}$ ) or proline ( $\mathrm{p} 53$ Pro) allele. We found that the p53Pro allele induced a higher rate of cell death than the p53Arg allele in all the three cell lines (Figure 2A, upper panel). Moreover, though p53Arg/p53Pro transfected cells showed similar levels of p53 protein (Figure 2A, lower panel), p53Arg allele-transfected cells expressed higher levels of hypoxia survival genes, namely
CA-IX, VEGF, HO-I, hepatocyte growth factor receptor (c-MET), and vascular endothelial growth factor receptor 2 (KDR), than p53Pro-transfected ones (Figure 2A, middle panel). At variance, the transfection of the $\mathrm{p} 53 \mathrm{Arg} / \mathrm{p} 53$ Pro alleles in absence of hypoxic environment, elicited a similar degree of cell death in HEP-3B cells as well as the p53Arg allele elicited a higher degree of cell death than the p53Pro in MDA-MB-157 and PC3 cells (Figure 2B). Since the genes above are regulated by the hypoxia response transcription factor HIF- $1 \alpha$ at the promoter level (Lee et al, 1997; Pal et al, 2001; Pennacchietti et al, 2003; Kaluzova et al, 2004), we then tested the hypothesis that the p53 codon 72 alleles exerts a direct regulation on HIF- $1 \alpha$ gene expression. We found that, in the presence of $<0.1 \% \mathrm{O}_{2}$, p53Arg allele-transfected MDA-MB-157 and PC- 3 cells, but not HEP3B, expressed a higher level of HIF- $1 \alpha$ gene mRNA than p53Pro-transfected ones (Figure 2C). Nevertheless, p53Arg-transfected HEP3B cells exposed to $100 \mu \mathrm{M}$ DFX, showed increased levels of HIF-1 $\alpha$, CA-IX and VEGF protein in respect to p53Pro-transfected ones (Figure 2D). These data suggest that the p53Pro allele hampers the capacity of cancer cells in 
a hypoxic environment by regulating HIF- $1 \alpha$ at transcriptional or post-transcriptional level, depending on the cell type examined.

\section{The p53Arg allele is retained in hypoxia-resistant, MCF-7 derived clones}

On the basis of the above results, it was reasoned that the p53Arg allele may be preferentially retained in heterozygote tumour cells owing to a survival advantage in presence of hypoxia. Following this hypothesis, we analysed the p53 codon72 genotype of 20 clones, obtained by the long-term exposure of the p53Arg/Pro heterozygote MCF-7 cell line to cytotoxic concentrations of DFX (see Supplementary Figure 1). PCR analysis revealed that all of the 20 clones obtained carried the p53Arg, but not the p53Pro allele (Supplementary Figure 1). HYPO-7 cells, the fastest growing clone, was further tested for the loss of heterozigosity at the p53 locus, by assessing the Intron I pentanucleotide repeat. The analysis confirmed that only one of the two allele present in parental MCF-7 cells was detectable in HYPO-7 cells (Figure 3A, upper panel). Interestingly, HYPO-7 cells maintained higher expression level of CA-IX, VEGF, HO-I, KDR mRNA than parental MCF-7 cells, even after several months of culture in absence of DFX (Figure 3A, lower panel, and Supplementary Figure 2). We then tested the capacity of the p53 codon 72 alleles to modulate the response to hypoxia in HYPO-7 cells. We found that, in the presence of $<0.1 \% \mathrm{O}_{2}$, the p53Pro allele transiently transfected cells exhibited a higher rate of cell death, (Figure 3B, upper panel), lower levels of CA-IX, VEGF, HO-I and KDR mRNA (Figure 3B, middle panel), as well as a lower level of HIF- $1 \alpha$ protein (Figure $3 \mathrm{~B}$, lower panel), compared to the p53Arg allele-transfected ones. To test further whether the p53 codon 72 alleles differ with regard to hypoxia survival in a MCF-7 genetic background, we transiently transfected pBabePuro-p53D stably-transduced MCF-7 cells with p53Pro/p53Arg alleles. In line with the results above, in the presence of $<0.1 \% \mathrm{O}_{2}$ the p53Pro allele elicited a higher degree of cell death, as well as lower levels of CA-IX, VEGF, HO-I mRNA, compared to the p53Arg allele (Figure $3 \mathrm{C}$ ). These data suggest that the loss of the p53Pro allele in p53 codon 72 heterozygous cancer cells is associated with a survival advantage in presence of hypoxia.

\section{DISCUSSION}

The present study provides evidence that the p53Pro allele of codon 72 locus confers a survival disadvantage to cancer cells in presence of hypoxia. This enhanced cell death inducing activity of the p53Pro allele in the presence of hypoxia, correlates with the lack of upregulation of a variety of genes (e.g., CA-IX, VEGF, c-MET, HO-I, KDR), whose promoters contain the consensus sequence for the hypoxia-induced transcription factor HIF-1 $\alpha$ (Lee et al, 1997; Pal et al, 2001; Pennacchietti et al, 2003; Kaluzova et al, 2004). Accordingly, we found that HIF- $1 \alpha$ protein and/or mRNA

\section{REFERENCES}

Alarcon R, Koumenis C, Geyer RK, Maki CG, Giaccia AJ (1999) Hypoxia induces p53 accumulation through MDM2 down-regulation and inhibition of E6-mediated degradation. Cancer Res 59: 6046-6051

Anzola M, Cuevas N, Lopez-Martinez M, Saiz A, Burgos JJ, de Pancorbo MM (2003) Frequent loss of p53 codon 72 Pro variant in hepatitis C virus-positive carriers with hepatocellular carcinoma. Cancer Lett 193: $199-205$

Baptiste N, Friedlander P, Chen X, Prives C (2002) The proline-rich domain of $\mathrm{p} 53$ is required for cooperation with anti-neoplastic agents to promote apoptosis of tumor cells. Oncogene 21: 9-21

Bergamaschi D, Gasco M, Hiller L, Sullivan A, Syed N, Trigiante G, Yulug I, Merlano M, Numico G, Comino A, Attard M, Reelfs O, Gusterson B, Bell AK, Heath V, Tavassoli M, Farrell PJ, Smith P, Lu X, Crook T (2003) p53 are decreased in cells transfected with the p53Pro allele. In this regard, it has been found that p53 downregulates HIF- $1 \alpha$ at the protein level, but also that p53 - / - cells exposed to hypoxia show an increase in HIF- $1 \alpha$ mRNA level in respect to p53 wild-type cells (Alarcon et al, 1999; Ravi et al, 2000; Nieminen et al, 2005). Hence, the available data support the hypothesis of a multilevel regulation of HIF- $1 \alpha$ gene expression by p53. In this paper, we also show that the exposure of arginine/proline heterozygote MCF-7 cells to the hypoxia-mimetic drug Desferoxamine, yields the outgrowth of arginine hemi-zygote clones. We propose that these results support the notion that the p53Pro allele confers a growth disadvantage in a hypoxic environment. Accordingly, the reintroduction of the p53Pro, but not the p53Arg allele in hypoxia selected cells downregulates hypoxia response genes and promotes hypoxia-induced cell death. At present, it is not clear whether the p53Arg carrier, hypoxia selected clones are a sub-population that is already present among parental MCF-7 cells, or arise as a consequence of a hypoxia-induced genomic DNA damage. It is worth noting, however, that no p53Pro hemi-zygote cells were obtained from MCF-7 cells exposed to DFX (data not shown). In conclusion, we propose that the result here presented may provide a functional explanation for the preferential retention of the p53Arg allele (the preferential loss of the p53Pro) in tumour tissues of p53 codon 72 heterozygote individuals. Moreover, these data may provide a functional cue for explaining the recently reported reduction in vivo of the amount of spontaneous cell death in the p53Arg-retaining tumours arisen in heterozygote individuals (Schneider-Stock et al, 2004). Finally, we suggest that our results contribute to explain the controversial association between p53 codon 72 polymorphism in cancer. Indeed, the p53Arg allele, though provides survival advantage to cancer cells in the presence of hypoxia, induces a higher susceptibility to cell death in absence of such a stress condition (this paper, Bonafe et al, 2002; Dumont et al, 2003; Bonafe et al, 2004). This behaviour adds up to a picture of the same genotype having different effects in tumour malignant progression depending on different microenvironmental conditions, for example, the oxygenation level.

\section{ACKNOWLEDGEMENTS}

This work has been supported by University of Bologna RFO funds-ex 60\%, Cornelia Pallotti and Roberto Pallotti Fundation to $\mathrm{MB}$ and by FIRB project to PC. We thank Wilma Mantovani and Daniela Bastia for cDNA sequencing analysis. We also thank Fondazione Cassa di Risparmio in Bologna for supporting the Centre for Applied Biomedical Research.

Supplementary Information accompanies the paper on British Journal of Cancer website (http://www.nature.com/bjc)

polymorphism influences response in cancer chemotherapy via modulation of p73-dependent apoptosis. Cancer Cell 3: 387-402

Bergamaschi D, Samuels Y, Sullivan A, Zvelebil M, Breyssens H, Bisso A, Del Sal G, Syed N, Smith P, Gasco M, Crook T, Lu X (2006) iASPP preferentially binds $\mathrm{p} 53$ proline-rich region and modulates apoptotic function of codon 72-polymorphic p53. Nat Genet 38: 1133-1141

Bonafe M, Ceccarelli C, Farabegoli F, Santini D, Taffurelli M, Barbi C, Marzi E, Trapassi C, Storci G, Olivieri F, Franceschi C (2003) Retention of the p53 codon 72 arginine allele is associated with a reduction of disease-free and overall survival in arginine/proline heterozygous breast cancer patients. Clin Cancer Res 9: 4860-4864

Bonafe M, Salvioli S, Barbi C, Mishto M, Trapassi C, Gemelli C, Storci G, Olivieri F, Monti D, Franceschi C (2002) p53 codon 72 genotype affects 
apoptosis by cytosine arabinoside in blood leukocytes. Biochem Biophys Res Commun 299: 539-541

Bonafe M, Salvioli S, Barbi C, Trapassi C, Tocco F, Storci G, Invidia L, Vannini I, Rossi M, Marzi E, Mishto M, Capri M, Olivieri F, Antonicelli R, Memo M, Uberti D, Nacmias B, Sorbi S, Monti D, Franceschi C (2004) The different apoptotic potential of the p53 codon 72 alleles increases with age and modulates in vivo ischaemia-induced cell death. Cell Death Differ 11: $962-973$

Brooks LA, Tidy JA, Gusterson B, Hiller L, O’Nions J, Gasco M, Marin MC, Farrell PJ, Kaeili Jr WJ, Crook T (2000) Preferential retention of codon 72 arginine p53 in squamous cell carcinomas of the vulva occurs in cancers positive and negative for human papillomavirus. Cancer Res 60: 6875-6877

Dumont P, Leu JI, Della Pietra III AC, George DL, Murphy M (2003) The codon 72 polymorphic variants of p53 have markedly different apoptotic potential. Nat Genet 33: 357-365

Graeber TG, Osmanian C, Jacks T, Housman DE, Koch CJ, Lowe SW, Giaccia AJ (1996) Hypoxia-mediated selection of cells with diminished apoptotic potential in solid tumours. Nature 379: $88-91$

Hammond EM, Giaccia AJ (2005) The role of p53 in hypoxia-induced apoptosis. Biochem Biophys Res Commun 331: 718-725

Hammond EM, Mandell DJ, Salim A, Krieg AJ, Johnson TM, Giaccia AJ (2006) Genome-wide analusis of p53 under hypoxic conditions. Mol Cell Biol 26: $3492-3504$

Kaluzova M, Kaluz S, Lerman MI, Stanbridge EJ (2004) DNA damage is a prerequisite for p53-mediated proteasomal degradation of HIF-1alpha in hypoxic cells and downregulation of the hypoxia marker carbonic anhydrase IX. Mol Cell Biol 24: 5757-5766

Koumenis C, Alarcon R, Hammond E, Sutphin P, Hoffman W, Murphy M, Derr J, Taya Y, Lowe SW, Kastan M, Giaccia A (2001) Regulation of p53 by hypoxia: dissociation of transcriptional repression and apoptosis from p53-dependent transactivation. Mol Cell Biol 21: 1297-1310

Lee PJ, Jiang BH, Chin BY, Iyer NV, Alam J, Semenza GL, Choi AM (1997) Hypoxia-inducible factor- 1 mediates transcriptional activation of the heme oxygenase-1 gene in response to hypoxia. J Biol Chem 272: $5375-5381$
Marin MC, Jost CA, Brooks LA, Irwin MS, O'Nions J, Tidy JA, James N, McGregor JD, Harwood CA, Yulug IG, Vousden KH, Allday MJ, Gusterson B, Ikawa S, Hinds PW, Crook T, Kaelin Jr WJ (2000) A common polymorphism acts as an intragenic modifier of mutant p53 behaviour. Nat Genet 25: 47-54

Matlashewski GJ, Tuck S, Pim D, Lamb P, Schneider J, Crawford LV (1987) Primary structure polymorphism at amino acid residue 72 of human p53. Mol Cell Biol 7: $961-963$

Nieminen AL, Qanungo S, Schneider EA, Jiang BH, Agani FH (2005) Mdm2 and HIF-1alpha interaction in tumor cells during hypoxia. J Cell Physiol 204: $364-369$

Pal S, Datta K, Mukhopadhyay D (2001) Central role of p53 on regulation of vascular permeability factor/vascular endothelial growth factor (VPF/ VEGF) expression in mammary carcinoma. Cancer Res 61: 6952-6957

Pennacchietti S, Michieli P, Galluzzo M, Mazzone M, Giordano S, Comoglio PM (2003) Hypoxia promotes invasive growth by transcriptional activation of the met proto-oncogene. Cancer Cell 3: 347-361

Per WS, Nolan GP, Scott ML, Baltimore D (1993) Production of high-titer helper-free retroviruses by transient transfection. Proc Natl Acad Sci USA 90: $8392-8396$

Ravi R, Mookerjee B, Bhujwalla ZM, Sutter CH, Artemov D, Zeng Q, Dillehay LE, Madan A, Semenza GL, Bedi A (2000) Regulation of tumor angiogenesis by $\mathrm{p} 53$-induced degradation of hypoxia-inducible factor 1alpha. Genes Dev 14: 34-44

Schneider-Stock R, Mawrin C, Motsch C, Boltze C, Peters B, Hartig R, Buhtz P, Giers A, Rohrheck A, Freigang B, Roessner A (2004) Retention of the arginine allele in codon 72 of the $\mathrm{p} 53$ gene correlates with poor apoptosis in head and neck cancer. Am J Pathol 164: 1233 - 1241

Semenza GL (2003) Targeting HIF-1 for cancer therapy. Nat Rev Cancer 3: $721-732$

Shaulian E, Zauberman A, Ginsgerg D, Oren M (1992) Identification of a minimal transforming domain of p53: negative dominance through abrogation of sequence-specific DNA binding. Mol Cell Biol 12: 5581-5592

Thomas M, Kalita A, Labrecque S, Pim D, Banks L, Matlashewski G (1999) Two polymorphic variants of wild-type p53 differ biochemically and biologically. Mol Cell Biol 19: $1092-1100$ 